\title{
Language use, home literacy environment, and demography: Predicting vocabulary skills among diverse young dual language learners in Norway
}

\author{
Veslemøy RYDLAND* (D) and Vibeke GRøVER \\ Department of Education, University of Oslo \\ ${ }^{*}$ Corresponding author: Professor Veslemøy Rydland Department of Education University of Oslo P.O. \\ Box 1092 Blindern 0317 OSLO Norway \\ Email: veslemoy.rydland@iped.uio.no
}

(Received 25 June 2019; revised 29 March 2020; accepted 23 July 2020;

first published online 7 October 2020)

\section{Introduction}

From a socio-cultural perspective, language offers a means for children to communicate with and learn from others through interaction: language is the medium through which young children are provided cognitive, social, and emotional support in interactions with caregivers, siblings, and peers; and children characterized as dual language learners (DLLs) have in common that they receive this developmental support in two different languages. However, due to variations in socioeconomic factors, ethnic/ immigration background, and language socialization practices, DLLs display considerable variability in their first- and second-language proficiency (McCabe, Tamis-LeMonda, Bornstein, Cates, Golinkoff, Guerra, Hirsh-Pasek, Hoff, Kuchirko, Melzi, Mendelsohn, Páez \& Song, 2013).

Vocabulary has been highlighted as an important indicator of language proficiency during the preschool years that has significant long-term consequences for both monolingual and bilingual children's academic achievement (Lervåg \& Grøver Aukrust, 2010; Mancilla-Martinez \& Lesaux, 2011). As recently argued by Snow (2017), vocabulary skills are also a proxy for children's accumulated knowledge about the world. A major challenge in research on DLLs, at least in many European countries, is that DLLs in the same preschool classrooms often speak very different first languages at home. This situation has likely skewed research toward studying only language groups for which validated first-language assessment instruments exist or, when mixed samples are addressed, focusing solely on DLLs' second-language skills. In the current study, we address these limitations and examine relative use of the first and second language at home as well as first- and second-language vocabulary development for children who live in families with highly diverse immigrant backgrounds in Norway. Some families were from Poland and Russia and had recently immigrated, others were from Pakistan and Turkey and had immigrated several decades ago. Some families were refugees from Somalia, others were of Tamil

( $)$ The Author(s), 2020. Published by Cambridge University Press. This is an Open Access article, distributed under the terms of the Creative Commons Attribution licence (http://creativecommons.org/licenses/by/4.0/), which permits unrestricted re-use, distribution, and reproduction in any medium, provided the original work is properly cited. 
origin and came to Norway to seek work but later to flee from Sri Lanka's Sinhalese authorities. Some families were immigrants from the Albanian ethnic group mainly fleeing wars in the Balkan province. The diverse sample also included families who were Arabs from Iraq, Morocco, Syria, and refugees from Vietnam. The main goal was to examine how use of the first and second language at home as well as demographic factors predicted first- and second-language vocabulary skills in these young DLLs who attend state-funded childcare settings in Norway.

\section{Literature review}

\section{Language use in the home and vocabulary development in DLLS}

Research on young DLLs has established a link between the relative amounts of first- and/or second-language use in the home and children's vocabulary levels in the respective languages (Dixon, Zhao, Quiroz \& Shin, 2012b; Duursma, RomeroContreras, Szuber, Proctor, Snow, August \& Calderón, 2007; Hammer, Davison, Lawrence \& Miccio, 2009; Hoff, Core, Place, Rumiche, Señor \& Parra, 2012; Place \& Hoff, 2016). However, most of this research on language use has focused on input, e.g., how much the child is exposed to a specific language in interactions with his or her parents (Scheele, Leseman \& Mayo, 2010) or across contexts (Hoff et al., 2012; Place \& Hoff, 2016; Palermo, Mikulski, Fabes, Hanish, Martin \& Stargel, 2014). Much less research has addressed young DLLs' use of the first and/or second language (but see Bohman, Bedore, Peña, Mendez-Perez \& Gillam, 2010). Such research endeavors are crucial because empirical studies have documented a discrepancy between parental exposure and children's use of the first and second languages in bilingual homes (Ribot \& Hoff, 2014; Ribot, Hoff \& Burridge, 2018). Young DLLs tend to productively use the first language less than do their parents, which may cause some children to exclusively develop a receptive command of the language primarily spoken by the significant adults in their lives (see the discussion in De Houwer, 2007). Young children also engage in interactions with peers, siblings, and grandparents in language environments that may differ from those provided by their parents (e.g., Rojas, Iglesias, Bunta, Goldstein, Goldenberg \& Reese, 2016; Rydland, Grøver Aukrust \& Fulland, 2013). Previous research suggests that DLLs may use the second language more with their siblings and peers than they do with their parents (Bridges \& Hoff, 2014). Indeed, several studies of preschool-age Spanish-English bilingual children in the United States have found that measures of the child's use (Bedore, Peña, Summers, Boerger, Resendiz, Greene \& Gillam, 2012; Hammer, Komaroff, Rodriguez, Lopez, Scarpino \& Goldstein, 2012) or a combined measure of exposure and use (Bohman et al., 2010) predicts young children's vocabulary skills. Although parental exposure and child use may differ, it is also reasonable to assume that there is a consistency in the child's respective language use across contexts such that children who use the first language with their parents are more inclined to use the first language with peers and siblings (see, for instance, De Houwer, 2007).

Although the developmental trajectories of young DLLs suggest that the children develop a distinct language system for each language, there is evidence that the two language systems interact. For instance, Winsler, Kim, and Richard (2014) found that better first-language skills in Spanish at age four predicted the attainment of second-language English proficiency by the end of kindergarten in a US sample (for similar findings in the Norwegian context, see Grøver, Lawrence \& Rydland, 2016; Karlsen, Lyster \& Lervåg, 2017). This research identifies a need to look at the unique 
factors that contribute to young DLLs' vocabulary development in the first and second language while keeping in mind the interdependencies between children's skill levels in the two languages.

\section{The role of demographic factors in young DLLs' vocabulary development}

Socioeconomic status (SES) is a compound variable that is frequently indexed by parental education and work. At the group-mean level, children from low-SES households develop vocabulary at a slower rate relative to children who grow up in higher SES homes (e.g., Fernald, Marchman \& Weisleder, 2013). The association between family SES and child language development is hypothesized to be mediated by proximal processes such as the amount and quality of talk exposure (e.g., Hoff, 2003; Lohndorf, Vermeer, Carcamo \& Mesman, 2018) and the home literacy environment (Ergül, Sarica, Akoglu \& Karaman, 2017; Prevoo, Malda, Mesman, Emmen, Yeniad, van Ijzendoorn \& Linting, 2014). For instance, the number of books in the home appears to be an important indicator of the home literacy environment that predicts vocabulary development (Karlsen et al., 2017). In a large-scale study of English-only-speaking children in the United States, Durham, Farkas, Hammer, Tomblin, and Catts (2007) found that the oral language skills the children had developed during the preschool years explained most of the effect of SES on elementary school performance. Thus, it appears to be of vital importance to understand the extent to which SES factors relate to DLLs' language development in the preschool period and whether aspects of the home literacy environment mediate such relationships. However, it has typically been more difficult to establish a link between SES factors and the vocabulary development of DLLs. Winsler, Burchinal, Tien, Peisner-Feinberg, Espinosa, Castro and De Feyter, (2014), for instance, found that parental education levels were more strongly associated with child outcomes among children from English-only-speaking households than among children who grow up in families that use another first language at home. Most of the studies that have detected a link between SES and vocabulary skills among young DLLs have reported on second-language vocabulary development (e.g., Rydland, Grøver \& Lawrence, 2014). In a study of toddlers exposed to Spanish and English, Place and Hoff (2016) found that girls exhibited more advanced second-language (English) skills than boys and also found that maternal education was positively related to the children's second-language skills. In contrast, neither gender nor maternal education was related to the children's first-language (Spanish) skills. A relatively similar finding was recently reported within the Norwegian context. In a study of preschool-aged children of Turkish immigrant parents in Norway, Westeren, Halberg, Ledesma, Wold and Oppedal (2018) found that both the maternal and paternal levels of education predicted the children's second-language (Norwegian) vocabulary scores but not their first-language (Turkish) vocabulary scores. In addition, the mother's age at the time of immigration appeared to significantly predict the children's second-language vocabulary scores.

Language use and competency in bilingual families is dynamic: it is likely to change over time as children and parents encounter new settings, such as preschool and work settings. Preschool attendance may, in particular, impact DLLs' second-language vocabulary skills. In a study targeting Urdu-Norwegian speaking DLLs, Karlsen et al. (2017) found that child age at introduction to the preschool childcare setting predicted second-language vocabulary skills both concurrently and longitudinally; 
however, an earlier entrance into a preschool childcare setting is often motivated by conditions related to parental education and work. Thus, it seems pertinent to include a broader range of demographic factors to understand whether the amount of time spent in preschool uniquely predicts young DLLs' relative language use and vocabulary skills. For instance, we still know very little about whether an early entrance into a second-language-dominant early-education setting negatively impacts DLLs' first-language vocabulary skills.

Some studies have found that immigrant parents who work outside the home and have higher levels of education also use the second language more at home (Bohman et al., 2010; Prevoo et al., 2014). The interdependencies between SES and the relative language use in bilingual homes are not straightforward and likely influenced by additional circumstances. Hammer et al. (2012), for instance, found that higher levels of parental education were associated with more use of the first language in a sample of Spanish-English DLLs.

The impediments related to identifying the demographic variables that determine conditions for first-language vocabulary development among children who grow up as DLLs is documented in research conducted among diverse language groups residing in different national contexts (Dixon, Wu \& Daraghmeh, 2012a; Dixon et al., 2012b; Hammer et al., 2012; Prevoo et al., 2014; Quiroz, Snow \& Zhao, 2010; Scheele et al., 2010), but the reasons are not entirely understood (see discussion in Place \& Hoff, 2016; Pena \& Halle, 2011). It may be that the instruments that assess first-language skills are less sensitive or less valid than the instruments that assess second-language skills when applied in language-minority contexts, that other, unmeasured factors influence first-language development in such contexts, or that unique characteristics of different immigrant groups (e.g., little variability in SES) impede the possibility of detecting potential relationships.

\section{Aims of the present study}

A distinct quality of the language environment of DLLs who have entered second-language-dominant preschool settings is that children and parents may not address each other in the same language. As most research focuses on parental exposure, it seems pertinent to investigate the role of the child's use of the first and second languages across contexts. Moreover, it should be noted that it has been difficult to determine which factors are most important in driving DLLs' language development because many child- and family-level factors co-vary with home-language use and child outcomes. As first-language skills typically provide the young children of immigrants with a source of cultural transmission and familial support, it is particularly urgent to better understand the mechanisms that drive first-language development. The present study draws on a diverse sample of 35-year-old DLLs who attended state-funded preschool settings in Norway.

The aims of this study are to better understand how child relative language use, family-level demographic factors, and the home literacy environment relate to young DLLs' first- and second-language vocabulary outcomes. More specifically, we asked the following research questions:

1) What are the relations between child relative language use (the extent to which the child uses the first and second languages in the home context) and firstand second-language vocabulary skills? 
2) What are the relations between family demographic factors (e.g., parental SES and length of residence in the host country, child age of preschool entrance) and children's first- and second-language vocabulary skills?

3) What are the relations between the number of books in the home (as a proxy for the home literacy environment) and children's first- and second-language vocabulary skills?

\section{Methods \\ Sample}

The target children of the present study $(\mathrm{N}=464)$ were 3 - to 5 -years old (234 boys and 230 girls), lived in or outside of the capital city of Oslo, and were identified by their parents as DLLs. The large majority of mothers (92\%) and fathers (92\%) were born outside of Norway and immigrated to Norway as young adults (mean age of immigration mothers: 22 years; fathers: 24 years). Eighty-five percent of the target children had siblings; $70 \%$ had older siblings. The sample comprised 11 different home-language groups: Albanian $(n=24)$, Arabic $(n=43)$, Bosnian/Serbian $(n=14)$, Polish $(n=45)$, Russian $(n=7)$, Somali $(n=65)$, Sorani Kurdish $(n=22)$, Tamil $(n=$ $35)$, Turkish $(n=28)$, Urdu $(n=94)$, and Vietnamese $(n=21)$. We also included a mixed group $(n=66)$ comprising children who spoke various first languages that were rarer in the Norwegian context (e.g., different African languages). Note that we were not able to assess the first-language skills of the children in this mixed group. Forty-five percent of the children had grandparents in Norway. All the target children attended state-funded preschool childcare settings (123 different classrooms) located in the neighborhoods where they lived. Preschools are available for children from the age of 1, but children enter this setting at different ages.

In Norway, preschools are typically age heterogeneous (e.g., children from 3 to 5 attend the same classrooms), and partly subsidized preschool classes are offered to DLLs in city areas that are densely populated by immigrants. Norwegian is the common language in these preschools.

The target children were recruited through their preschools as part of a larger language-based intervention study (Grøver, Rydland, Gustafsson \& Snow, 2020). In the present study, we use the pre-intervention data that were collected as part of the overall project. Letters requesting written consent in the child's first and second languages were distributed to the parents through the preschools. We recruited a mean number of 3.77 children per class. The preschools attended by the target children were strikingly multiethnic: among the mean level of 18 children per classroom, 11 children had both a mother and a father who spoke another first language than Norwegian at home. In addition, a mean of 5 children per classroom had one parent who spoke another first language at home.

\section{Vocabulary measures}

The target children's second-language vocabulary skills were assessed with three different measures: one standardized receptive vocabulary assessment instrument (the British Picture Vocabulary Scale II) and two researcher-developed vocabulary assessment instruments (L2 Voc Receptive and L2 Voc Expressive). Further description of the test development process is provided under Procedures below. 
The British Picture Vocabulary Scale II (BPVS-2) (Dunn, Dunn, Whetton \& Burley, 1997) has been adapted into Norwegian (Lyster, Horn \& Rygvold, 2010). Each child was shown successive panels of four pictures and asked to point to the picture that matched the word said by the assessor. The child was given one point per correct response, and stop rules were used.

The L2 Voc Receptive test in Norwegian comprises 46 items and was administered based on procedures that resembled the BPVS-2: the assessor said one word and the child had to select the corresponding picture based on four drawings. No start or stop rules were applied, and the child was given one point per item (examples of word items: frog, ostrich, audience, float, jealous, and ripe).

The L2 Voc Expressive measure comprises nine items and was developed to assess children's skills at defining and describing words (e.g., What does invisible mean?). No start or stop rules were applied when administering the test. Children's responses were coded along a three-point scale from 0 to 2. Children were given a score of 0 for not responding or responding incorrectly (e.g., when defining the word invisible, they said "stealing something") and a score of 1 for demonstrating some understanding or mentioning one characteristic out of several possible (e.g., invisible means "being gone" or "to use magic"). The child was given a score of 2 if he or she included several characteristics of the item or showed more in-depth conceptual knowledge (e.g., "someone is there, but you cannot see them"). The Cohen's kappa calculated for the scoring of interrater reliability was 0.86 .

The target children's first-language vocabulary skills were assessed with translated versions of the Voc Receptive and Voc Expressive assessments (see the further description of the translation process under Procedures below). The L1 Voc Receptive measure comprises 43 items; three out of the 46 word items in the Norwegian version were excluded from the final first-language measure as we were unable to find an equivalent word item that we deemed to be appropriate in one or more of the 11 languages. The L1 Voc Expressive assessment in the different first languages comprises eight items. The word peace, which appears in the Norwegian version of the test, could have various meanings when translated into one of the 11 first languages; thus, this word item was excluded from the final L1 Voc Expressive measure. Table 1 presents the Cronbach's alpha for the vocabulary measures and the target children's first-and second-language vocabulary scores. Note that the relatively few items in the expressive tasks may reduce the value of alpha. Nonetheless, the Cronbach's alpha values ranged from .74 to .93, suggesting fairly good internal consistency across measures. As can be seen in the table, the children in the present sample demonstrated higher scores in their first-language receptive vocabulary despite the fact that the possible obtainable score was higher in the second-language assessment (three items were removed from the first-language assessments).

\section{Procedures}

Assessment of first- and second-language vocabulary skills

Assessment of the target children's vocabulary skills was conducted in the preschools that the children attended, by trained assessors who were fluent in the language of assessment. First- and second-language assessments were separated by at least one week. Children's mean age in months was 52.6 at the time of the Norwegian assessment and 53.2 at the time of the first-language assessment. We were able to assess the first-language vocabulary skills of 332 children. 
Table 1. Child Vocabulary Scores; Cronbach's Alpha, Means and Standard Deviations

\begin{tabular}{lccc}
\hline & $\alpha$ & $N$ & $M(S D)$ \\
\hline L1 VOC RECEPTIVE & .74 & 332 & $18.49(6.01)$ \\
\hline L1 VOC EXPRESSIVE & .74 & 331 & $0.73(1.57)$ \\
\hline BPVS-2 & .93 & 439 & $27.00(13.42)$ \\
\hline L2 VOC RECEPTIVE & .74 & 446 & $14.85(5.69)$ \\
\hline L2 VOC EXPRESSIVE & .88 & 444 & $0.81(1.56)$ \\
\hline
\end{tabular}

The Voc Receptive and Voc Expressive assessments were developed by our research team in order to measure the effect of the forthcoming intervention and meet the need for assessment instruments that we could also translate into the many different first languages. We used mixed methods to construct and validate the assessment instruments. The words in the test were drawn from a longer list of Norwegian words that were selected from a varied sample of children's books. In the selection process, we collaborated with a reference group of experienced preschool teachers who used the words with the children in their classrooms and then offered feedback about the appropriateness of the words, etc. The first versions of the researcher-developed vocabulary tests were piloted in Norwegian with preschool children. The tests were revised based on analyses of item difficulty and discrimination as well as responses to the distractors (in the receptive test).

The Norwegian version of the Voc Receptive and Voc Expressive assessment instruments were then translated into the 11 first languages in the project. We began the translation process by using a professional translation firm that was given access to the test material. The items were then back-translated to Norwegian by the project's bilingual research assistants (who had academic backgrounds either in linguistics or education). Translated items that yielded a more or less prevalent word in a specific language relative to the corresponding item in the Norwegian version (i.e., the target word residence translated into the word house) were then discussed by the research team to find a more appropriate translation.

During the thorough process of identifying the most appropriate translation of individual word items, we also consulted other bilingual speakers (e.g., parents) with knowledge of the preschool children's word use and preferences in each language. Comparable word frequency lists were not available across all home-language groups and may not be suitable for young children who grow up in a language-minority context. In most instances, we were able to agree on a translation of the various word items that were appropriate in terms of level of abstractness and prevalence. However, it should be noted that we approached this task fully aware that it would not be possible to identify words or expressions across the 11 different first languages that were equivalent in terms of difficulty level and frequency (for discussion, see Pena \& Halle, 2011).

Further inspection of item difficulty in the L1 Voc Receptive assessment revealed that the majority of items were in the mid-range. None of the items were deemed too easy (answered correctly by more than $80 \%$ of the sample) or too difficult (answered correctly by less than $20 \%$ of the sample). Six items discriminated poorly (the correlations with the overall test results were below 0.10). However, we did 
detect differences in item difficulty levels across the first-language assessments. For example, while no items were deemed too easy in the Somali assessment, seven items appeared to be too easy in the Polish assessment (more than $80 \%$ of the children answered these items correctly). Overall, only two items in the Somali and one item in the Polish receptive vocabulary assessment were deemed too difficult (answered correctly by less than $20 \%$ of the children). Translation issues as well as differences in the overall first-language proficiency among children in the home-language groups may explain these dissimilarities across first-language assessments.

\section{Information about first- and second-language use at home and demographics}

Trained bilingual research assistants conducted telephone interviews based on questionnaires with either the mother or the father of each target child in the parents' preferred language. The interviewee provided information about him or herself and the other parent.

In these structured interviews, parents reported on maternal and paternal language use, respectively, when speaking to the child (resulting in two indicators of language exposure) as well as the child's language use when speaking to the mother, father, grandparents, siblings, and children of extended family/family friends (resulting in five indicators depicting the child's relative language use). All responses for relative language use were scored on a scale from 1 to $3(1=$ mostly first language, $2=$ both first language and Norwegian, 3 = mostly Norwegian). Table 2 presents first-language use (percentages in the sample that reported using the first language or the first and second languages to the same extent) and the number of respondents for each language-use variable. As seen in the table, the parents reported extensive use of the first language when addressing the child, while the children tended to address their parents in the first language much less. It should be noted that the children in the Polish and Turkish home-language groups appeared most inclined to use the first language with their parents: $95 \%$ of the children in the Polish group and $77 \%$ of the children in the Turkish group reported using the first language when addressing their mothers.

The vast majority of the grandparents used the first language when addressing the child and many children also used the first language to some extent when addressing their grandparents. Although this pattern of relative language use is not surprising, it demonstrates that grandparents constitute an important context for young DLLs' first-language exposure and use. About half of the children in the sample mostly used the second language with siblings and other children of extended family/family friends.

Parents also reported demographic information related to the child's age in months at preschool entrance $(n=420)$, maternal $(n=418)$ and paternal $(n=397)$ length of residence in Norway (calculated in years), whether the parents were studying/ working outside the home (mothers: $n=416$; fathers: $n=395$ ), and parental level of education. Maternal $(n=398)$ and paternal $(n=373)$ levels of education were scored on a scale from 1-6 $(1=0-4$ years of schooling, $2=5-7$ years of schooling, $3=$ junior high school, $4=$ high school, $5=$ bachelor's, $6=$ master's or more).

About $50 \%$ of the target children had entered preschool at or before 24 months of age (age in months at preschool entry: $\mathrm{M}=26.11, \mathrm{SD}=10.73$ ). There appeared to be large variability in parental years of residence in Norway (mothers: $\mathrm{M}=11.51, \mathrm{SD}=7.49$; fathers: $M=13.67, \mathrm{SD}=8.58$ ). Not surprisingly, the Polish-speaking parents had resided in Norway for the shortest duration (mothers: $M=6.26, S D=3.41$; fathers: $M$ $=6.61, \mathrm{SD}=2.82$ ). Furthermore, there was a substantial range in parental level of education. The mean level of maternal education was $3.99(\mathrm{SD}=1.27)$, and the mean 
Table 2. Percentages of Sample Reporting Mostly First-Language Use or a Combination of First- and Second-Language Use

\begin{tabular}{llc}
\hline & $N$ & $\%$ \\
\hline Mother to child & 411 & $91 \%$ \\
\hline Child to mother & 409 & $58 \%$ \\
\hline Father to child & 382 & $90 \%$ \\
\hline Child to father & 379 & $63 \%$ \\
\hline Grandparents to child & 189 & $95 \%$ \\
\hline Child to grandparents & 187 & $76 \%$ \\
\hline Child to siblings & 344 & $48 \%$ \\
\hline Child to other children of friends/family & 423 & $47 \%$ \\
\hline
\end{tabular}

level of paternal education was $4.13(\mathrm{SD}=1.18)$, which shows that the average length of education was the completion of high school. The majority of parents worked or studied outside the home, although fewer mothers (63\%) than fathers (79\%) were engaged in work or schooling.

Finally, based on a scale scored from 1 to $4(1=0-2$ books, $2=3-10$ books, $3=11-$ 50 books, $4=$ more than 50 books), parents reported the number of books for children and adults in the first and second language that the family owned. It is worth noting that parents in this sample generally reported low numbers of books for children (first language: $\mathrm{M}=1.77, \mathrm{SD}=0.92$; second language: $\mathrm{M}=2.52, \mathrm{SD}=0.73$ ) and books for adults (first language: $\mathrm{M}=1.97, \mathrm{SD}=1.04$; second language: $\mathrm{M}=2.00, \mathrm{SD}=0.85$ ) in the home. The vast majority of the families (79\%) had ten books or fewer in the first language. The families appeared to own more children's books in their second-language than in their first language (about 50\% owned 10 books or fewer in the second language). Only the Polish-speaking families had a slightly different profile: they reported owning more books in the first language, Polish, than in the second language, Norwegian.

\section{Analysis of the data}

We used a structural equation modeling (SEM) approach with latent variables to predict first- and second-language vocabulary skills. Latent variables take only the common variance among observed variables into account, enabling the testing of statistical relationships without measurement errors. We created latent variables for child relative language use, SES, the number of first-language books in the home, the number of second-language books in the home, first-language vocabulary skills, and second-language vocabulary skills. To address research questions 1 and 2, first- and second-language vocabulary skills were regressed on child relative language use and SES. We also included observed demographic variables (child's age in months at preschool entrance, parental years of residence in Norway, and gender) as predictors.

Preliminary analyses revealed that the number of books in the home was strongly associated with other main predictor variables in the study (such as SES and relative language use), and thus became confounders when entered into the same analysis. For this reason, we conducted a new analysis to address research question 3. In this 
analytic model, SES was replaced with the number of first-language books and the number of second-language books as predictors of first- and second-language vocabulary skills, respectively. Preliminary analyses also revealed that the children's first-language vocabulary skills varied across the home-language groups, while second-language vocabulary skills were less clearly related to such grouping differences. Thus, in preliminary analyses, we ran separate analyses including the six most robust home-language groups (Arabic, Polish, Somali, Tamil, Turkish, and Urdu) as dummy-coded predictors of first- and second-language vocabulary outcomes. When we report on the best-fitted model to address research question 3 in the Results section, we include the home-language groups that differed from other children in the sample in terms of vocabulary skills once other factors in the model were accounted for. In a final set of analyses, we tested whether the two latent constructs of first- and second-language books in the home mediated the relationships between SES and children's first- and second-language vocabulary skills, respectively.

Due to the variations in age, we controlled for the child's age in months at the time of the outcome assessments in all analyses. Because children were recruited from different preschool classrooms, we accounted for the clustering of scores within classrooms using the complex option in the Mplus program (Muthén \& Muthén, 1998-2017). The model-based maximum-likelihood procedures implemented in Mplus were relied on to handle missing data.

We evaluated the model fit against the following guidelines. The Root Mean Squared Error of Approximation (RMSEA) estimate should be lower than .05, and the upper limit of its $90 \%$ confidence interval should be lower than .08. The Comparative Fit Index (CFI) should be higher than .90 and the Tucker Lewis Index (TLI) should be higher than 0.90. Finally, the square-root of the difference between the residuals of the sample covariance matrix and the hypothesized model (the Standardized Root Mean Square Residual, SRMR) should be lower than .08.

In the following presentation of results from the SEM analyses, we report the standardized coefficients.

\section{Results}

As Table 3 shows, three vocabulary measures were used as indicators of a common second-language vocabulary construct: BPVS-2, L2 Voc Receptive, and L2 Voc Expressive. The latent second-language vocabulary construct loaded significantly on the three indicators. Since we did not have first-language BPVS assessments, only two observed measures were used to build a latent first-language vocabulary assessment: L1 Voc Receptive and L1 Voc Expressive. In the initial analyses, we saw that the children's relative language use when respectively addressing their mothers and fathers predicted vocabulary outcomes more strongly than parental relative language use when addressing the child. Thus, we decided to build a latent construct of child relative language use. This construct comprised five indicators: child relative language use when addressing 1) the mother, 2) the father, 3) grandparents, 4) siblings, and 5) children of family friends/extended family. The fact that all these indicators loaded significantly on the same latent construct suggests consistency in the target children's relative language use with different communication partners in the family context. The variables maternal education, paternal education, maternal work, and paternal work were used as indicators of SES. Since we expected that the 
Table 3. Standardized Parameter Estimates for the Latent Variables. First-and Second language Vocabulary Skills, Child Relative Language Use, SES and the Number of Books in the Home

\begin{tabular}{lllll}
\hline & $\beta$ & $S E$ & $t$-value & $p .<$ \\
\hline L1 Vocabulary & & & & \\
\hline L1 VOC RECEPTIVE & 0.79 & 0.038 & 20.73 & .001 \\
\hline L1 VOC EXPRESSIVE & 0.66 & 0.044 & 14.99 & .001 \\
\hline L2 Vocabulary & & & & \\
\hline BPVS-2 & 0.86 & 0.022 & 39.20 & .001 \\
\hline L2 VOC RECEPTIVE & 0.75 & 0.026 & 28.38 & .001 \\
\hline L2 VOC EXPRESSIVE & 0.67 & 0.034 & 19.80 & .001 \\
\hline Child use & & & & \\
\hline Mother & 0.83 & 0.028 & 29.95 & .001 \\
\hline Father & 0.82 & 0.031 & 26.15 & .001 \\
\hline Grandparents & 0.61 & 0.045 & 13.54 & .001 \\
\hline Siblings & 0.73 & 0.042 & 17.46 & .001 \\
\hline Family friends & 0.60 & 0.047 & 12.82 & .001 \\
\hline SES & & & & .001 \\
\hline Maternal education & 0.77 & 0.065 & 11.89 & .001 \\
\hline Paternal education & 0.66 & 0.052 & 12.63 & .001 \\
\hline Maternal work & 0.34 & 0.067 & 5.11 & .001 \\
\hline Paternal work & 0.42 & 0.064 & 6.56 & .001 \\
\hline L1 books & 0.77 & & & .001 \\
\hline Books for children & 0.57 & 0.053 & 9.29 & \\
\hline Books for adults & & & & \\
\hline L2 books & 0.61 & 0.045 & \\
\hline Books for children & & & & \\
\hline Books for adults & & & & \\
\hline & & & & \\
\hline
\end{tabular}

number of first-language books in the home would be more dependent on availability in specific heritage languages compared to the number of second-language books, we decided to separate these into two different constructs: the number of first-language books (for adults and children) and the number of second-language books (for adults and children). As can be seen in Table 3, all constructs loaded significantly on their respective indicators.

\section{Child relative language use and family demographics as predictors of vocabulary}

In order to answer the first two research questions, the latent variables first- and second-language vocabulary skills were regressed on the latent variables child relative language use and SES. Additional observed predictor variables were child age in months, 
child age at preschool entry, child gender, and maternal and paternal years of residence. This model had good fit (Goodness of fit: $\chi^{2}=255.59$, $d f=133, p<.001$; RMSEA = $\left.0.045, \mathrm{CI}_{90}=0.036-0.053 ; \mathrm{CFI}=0.934 ; \mathrm{TLI}=0.914 ; \mathrm{SRMR}=0.049\right)$. The standardized model results are illustrated in Figure 1. The figure only depicts the relationship between the latent variables. Both first- and second-language vocabulary skills appeared to be predicted by child relative language use, but there was an interesting difference in the strength of these relationships: relative language use had a relatively strong standardized partial regression on first-language vocabulary skills $(\beta=-0.38, t=6.45, p<.001)$ and a small standardized partial regression coefficient on second-language vocabulary skills $(\beta=0.14, t=2.58, p<.01)$. The negative estimate of the association between relative language use and first-language vocabulary skills reveals that children who used the first-language more (lower scores for relative language use) had more developed first-language vocabulary skills. In addition, SES explains significant variance in both first- and second-language vocabulary skills in the model (respectively $\beta=0.30, t=4.57$, $\mathrm{p}<.001$ and $\beta=0.18, t=3.63, p<.001)$. The variance in the latent construct second-language vocabulary skills is also predicted by age at preschool entry $(\beta=-0.23$, $t=-4.45, p<.001)$. The negative estimate suggests that children who were younger at preschool entry had stronger second-language vocabulary skills. Children also had stronger second-language vocabulary skills if their mothers had resided in Norway for a longer duration $(\beta=0.10, t=2.25, p<.05)$ and if they were girls $(\beta=-0.09, t=2.30$, $p<.05$ ), but it should be noted that these relations were not very strong. Somewhat different factors explained the variance in first-language vocabulary skills beyond the effects of child relative language use and SES. Age at preschool entry was not significantly linked to children's first-language vocabulary skills $(\beta=0.02, t=0.06$, $p=.685$ ). This finding suggests that children who entered the Norwegian preschool setting at an earlier age were not at a disadvantage in terms of maintaining first-language vocabulary skills compared to children who had entered preschool when they were older. As expected, an early entrance into preschool was slightly more prevalent in higher-SES families $(r=-0.16, t=-2.73, p<.01)$. Gender did not explain unique variance in first-language vocabulary skills in this model $(\beta=-0.06, t=-1.02$, $p=.306$ ). Both maternal and paternal years of residence in Norway had a small standardized partial regression coefficient on the children's first-language vocabulary skills $(\beta=-0.15, t=-2.73, p=.01$ and $\beta=-0.14, t=-2.39, p=.05$, respectively) beyond the strong effects of child relative language use and SES. The negative estimates suggest that mothers and fathers with fewer years of residence in Norway had children with stronger first-language vocabulary skills.

We did not detect a relationship between child relative language use and SES $(r=.01$, $t=0.16, p=.876)$. This finding implies that children in both higher- and lower-SES homes maintained productive use of the first language with significant others in their lives. Finally, the analytic model reveals a strong relationship between the two latent constructs of first- and second-language vocabulary skills $(r=.48, t=5.02$, $p<.001$ ), suggesting that the two are separable but also clearly interdependent abilities among the young DLLs in the present sample.

\section{The number of first- and second-language books in the home as predictors of vocabulary skills}

In order to further investigate the role of the home literacy environment (the number of books in the home) on first- and second-language vocabulary scores, we ran a new SEM 


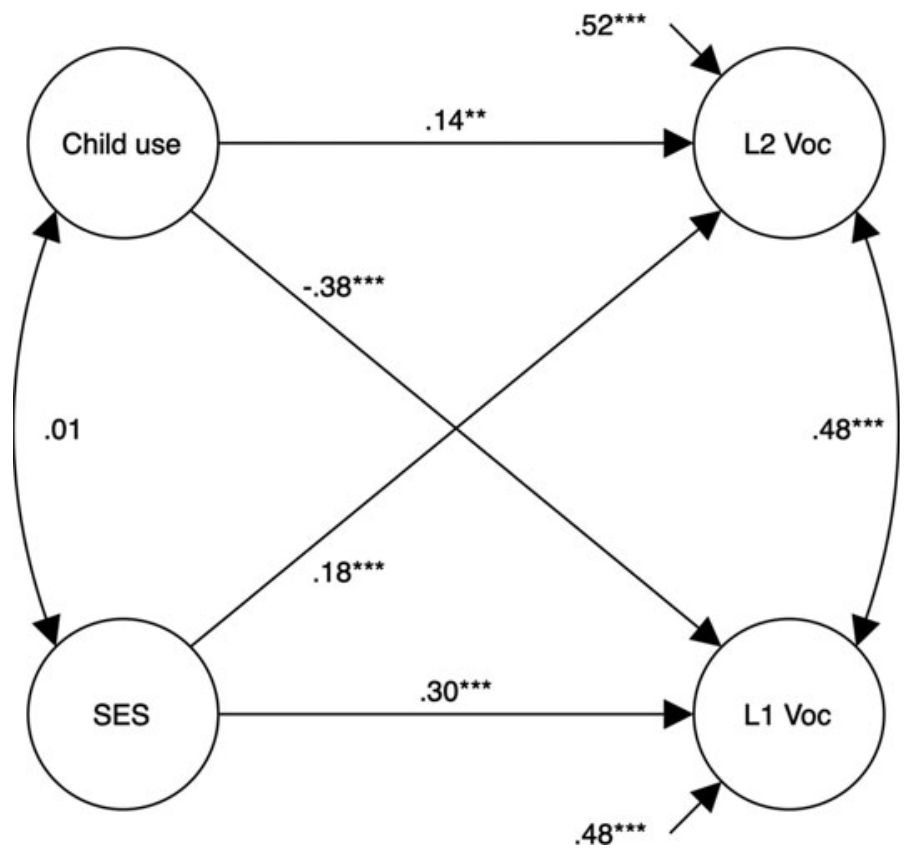

Figure 1. First-and Second Language Vocabulary Skills Regressed on Child Relative Language Use and SES ${ }^{\star \star} p<.01,{ }^{\star \star \star} p<.001$. Regressions are shown by one-headed arrows between variables. Correlations are shown by two-headed arrows between variables. Residual variances are illustrated by one-headed arrows from a number to the endogenous variables. Observed predictor variables are not included in the figure.

model. This second model differed from the first model in that SES was replaced by the number of books in the home and also included the home-language groups that accounted for additional variance in vocabulary skills. This model fitted the data well (Goodness of fit: $\chi^{2}=247.67, d f=135, p<.001$; RMSEA $=0.043, \mathrm{CI}_{90}=0.034-0.051$; $\mathrm{CFI}=0.947 ; \quad \mathrm{TLI}=0.926 ; \quad \mathrm{SRMR}=0.042)$. The standardized model results are illustrated in Figure 2 (the figure depicts the relationship between the latent variables as well as one of the home language groups).

The number of first-language books in the home had a standardized partial regression for first-language vocabulary skills $(\beta=0.38, t=3.81, p<.001)$.

Child relative language use no longer explained unique variance in first-language vocabulary skills once the number of first-language books in the home was included in the model $(\beta=-0.08, t=-1.06, p=.290)$. Child relative language use was highly correlated with the number of first-language books in the home $(r=-0.55, t=-9.81$, $p<.001$ ), suggesting that children who used the first language more also lived in families with a stronger home literacy environment in the first language. Furthermore, the number of second-language books in the home had a standardized partial regression on second-language vocabulary skills $(\beta=0.21, t=3.36, p<.01)$. However, this relationship did not fully eliminate the effect of child relative language use on second-language vocabulary skills $(\beta=0.13, t=2.44, p<.05)$. Indeed, the number of second-language books in the home and child relative language use were weakly correlated $(r=0.18, t=2.34, p<.05)$ in this model, suggesting that child use 


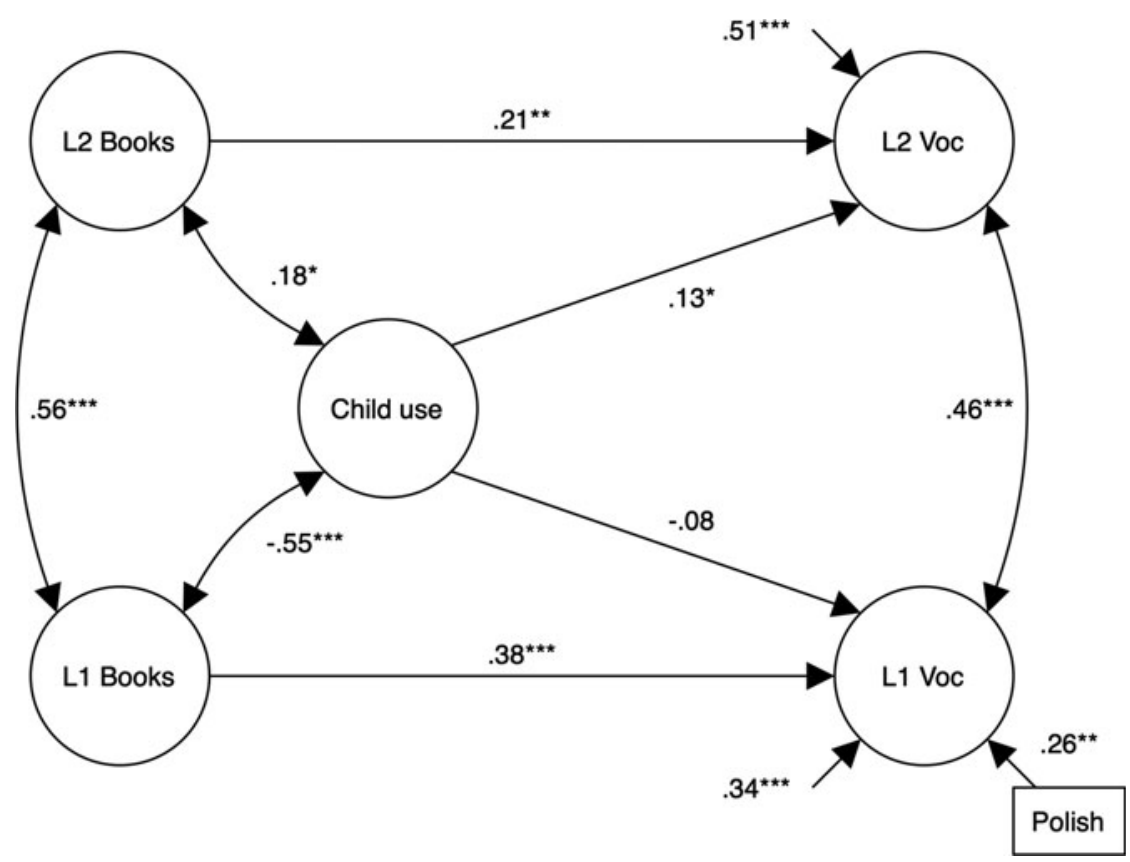

Figure 2. First-and Second Language Vocabulary Skills Regressed on Child Relative Language Use and the Number of Books in the Home

${ }^{\star} P<.05,{ }^{\star \star} p<.01,{ }^{\star \star \star} p<.001$. All coefficients are standardized. Regressions are shown by one-headed arrows between variables. Correlations are shown by two-headed arrows between variables. Residual variances are illustrated by one-headed arrows from a number to the endogenous variables. Only one of the observed predictor variables (Polish) is included in the figure.

of the second language was only to some extent related to whether the families owned many books in Norwegian.

None of the home-language groups had stronger second-language vocabulary skills compared to the overall sample. However, the Polish home-language group had significantly stronger first-language vocabulary scores $(\beta=0.26, t=3.15, p<.01)$.

Consistent with the first model, most of the previously described relationships were maintained in the second analytic model, apart from the fact that parental years of residence appeared to be less influential: only paternal years of residence had a small standardized partial regression on first-language vocabulary skills once the Polish home-language group and the home literacy environment were included in the model $(\beta=-0.14, t=-2.39, p<.05)$. The variable maternal years of residence in Norway was strongly related to other variables in the model: mothers who had resided in Norway for a longer duration had children who used the second language more $(r=0.27, t=$ 4.17, $p<.001)$ and owned more books in the second language $(r=0.28, t=4.26, p$ $<.001)$. Families in which the mother had resided in Norway for a shorter duration owned more books in the first language $(r=-0.20, t=-3.47, p<.01)$.

To further investigate whether the significant relationship between SES and children's first-language vocabulary skills was mediated by characteristics of the home literacy environment such as the number of first-language books in the home, we built a new model encompassing these three latent constructs. This analysis is illustrated in Figure 3. 


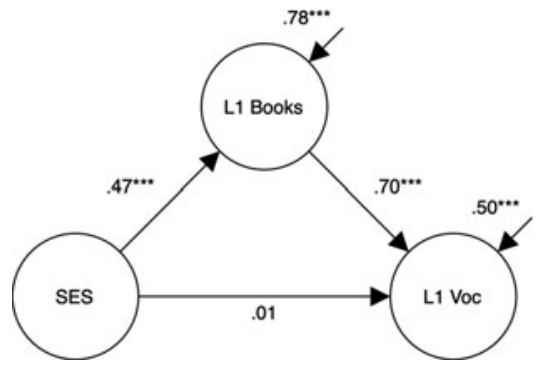

Figure 3. L1 Books Mediating the Effect of SES on L1 Vocabulary

${ }^{\star \star \star} p<.001$. Regressions are shown by one-headed arrows between variables. Residual variances are illustrated by one-headed arrows from a number to the endogenous variables.

The model fit was good (goodness of fit: $\chi^{2}=41.84, d f=23, p<.01 ; \mathrm{RMSEA}=0.049, \mathrm{CI}_{90}=$ 0.024-0.073; CFI $=0.954$; TLI $=0.928$; SRMR $=0.049$ ). The initial total effect of SES on first-language vocabulary skills $(\beta=0.34, t=4.92, p<.001)$ appeared to be fully mediated by the number of first-language books in the home: SES had a significant standardized partial regression coefficient on the number of first-language books in the home $(\beta=$ $0.47, t=5.53, p<.001)$, and the number of first-language books in the home had a strong standardized partial regression coefficient on first-language vocabulary skills $(\beta=$ $0.70, t=6.30, p<.001)$. After the number of first-language books was included as a mediating variable, the effect of SES on first-language vocabulary skills was no longer significant $(\beta=0.01, t=0.09, p=.925)$.

Similarly, as illustrated in Figure 4, we investigated the extent to which the number of second-language books in the home mediated the relationship between the latent construct SES and second-language vocabulary skills. This latent model fitted the data well (goodness of fit: $\chi^{2}=55.72, d f=30, \mathrm{p}<.01$; RMSEA $=0.043, \mathrm{CI}_{90}=0.025$ 0.060 ; CFI $=0.970$; TLI $=0.955$; SRMR $=0.041)$. The initial total effect of SES on second-language vocabulary skills $(\beta=0.26, t=4.06, p<.001)$ also appeared to be strongly mediated by the number of second-language books in the home: SES had a significant standardized partial regression coefficient on the number of second-language books in the home $(\beta=0.49, t=5.27, \mathrm{p}<.001)$, and the number of second-language books in the home had a moderate standardized partial regression coefficient on second-language vocabulary skills $(\beta=0.34, t=3.90, p<.001)$. After the number of second-language books was included as a mediating variable, the standardized partial regression coefficient of SES for second-language vocabulary skills was no longer significant $(\beta=0.09, t=1.19, p=.235)$.

\section{Discussion}

This study has demonstrated that the home literacy environment, which appears to be closely intertwined with child relative language use and family demographic factors, was a marked predictor of young DLLs' first- and second-language vocabulary skills. In addition, children had stronger second-language vocabulary skills if they had attended preschool for a longer duration and if they were girls. The findings related to child relative language use, family demographics, and the home literacy environment will be further elaborated on and discussed below. 
Firstly, the present study revealed that the quantity of relative language use matters, as previously reported in De Houwer (2007), Gathercole and Thomas (2009), Hoff et al. (2012), and Scheele et al. (2010). Interestingly, the analysis of various usage indicators pointed to the importance of capturing young DLLs' productive use of the first and second languages in the home context. This finding alludes to the study by Bohman et al. (2010), who reported that exposure appeared to be important for young Spanish-English DLLs as they begin to learn a language and that productive use was more important as they add knowledge to their languages. It is noteworthy that the fairly simple measures of child relative language use across contexts (with parents, grandparents, siblings, and friends) were so predictive of the children's vocabulary skills in the present study. This finding suggests that parental reports may be seen as valid tools to assess language use in young DLLs, particularly if these measures capture the child's productive use of the two languages across contexts. The fact that SES factors appeared to be unrelated to child relative language use suggests that the extent of first language use in the home context did not differ between children in higher and lower SES families. However, the findings in the present study do suggest that the home literacy environment may be more important in explaining differences in first-language vocabulary skills than parental reports of child relative language use. This finding resonates with the broad research literature demonstrating that young children's vocabulary skills are sensitive to the quality of the home environment (e.g., Lohndorf et al., 2018). Hence, it is worth noting that while SES was unrelated to child relative language use, there was a significant relationship between the home literacy environment and child relative language use.

Secondly, a somewhat puzzling finding in previous research has been the lack of an association between SES factors and child first-language outcomes. It is therefore a significant contribution of the present study that we detected a link between SES (assessed as parental education and work) and first- and second-language vocabulary outcomes. This finding supports the notion that parents in higher SES homes may provide conditions for language support that affect children's first- and second-language vocabulary outcomes (see, for instance, Quiroz et al., 2010). Indeed, follow-up mediation analyses suggested that the number of first-language books in the home fully mediated the association between SES and first-language vocabulary skills and that the number of second-language books in the home mediated the relation between SES and second-language vocabulary skills. The number of books in the home has been shown to be an important indicator of the home literacy environment (e.g., Karlsen et al., 2017), and the findings of the present study indicate that it may be important to distinguish between books in the first and second language. Moreover, the fact that the number of first-language books in the home predicted first-language vocabulary scores extends a study by Prevoo et al. (2014), who found that reading input mediated the relation between SES and second-language vocabulary in a Turkish-Dutch speaking sample.

A third major finding of the present study is that the duration of preschool attendance was related to second-language vocabulary outcomes even though the target children attended preschool contexts that included very few other children who were first-language speakers of Norwegian. This finding underscores the importance of the preschool context for second-language learning, although observational measures of the quality of language interactions in the classrooms would be necessary to shed light on whether mere time spent in preschool constitutes a unique predictor of second-language proficiency in DLLs (see, for 
instance, Rydland et al., 2014). It is worth noting that gender was only associated with second-language vocabulary skills in the present study: girls appeared to have slightly stronger second-language vocabulary scores than boys. The fact that the target children were mainly exposed to the second language in preschool suggests that future studies should investigate whether girls who are DLLs may be offered, or provide for themselves, more optimal contexts for second-language learning compared to boys who are DLLs. It is also important to note that the duration of preschool attendance did not appear to negatively impact on children's first-language vocabulary skills. That being said, this study also identified a distinct discrepancy between the language mostly used by the parents when addressing the child and the language mostly used by the child when addressing the parents. The fact that so many of these young DLLs already exhibit a preference for communication in the second language may not be surprising given the fact that they are all exposed to the second language in preschool. Nonetheless, it is noteworthy that this language shift happens even in families in which both the mother and father are inclined to communicate with the child in the first language. On the one hand, it is important to underscore that language mixing is a prevalent feature in multilingual situations that represent a resource for dual language learning and communication. On the other hand, the incongruity in parental and child relative language use is also a reminder that the heritage language exposure offered by parents may not be enough to ensure young DLLs' productive use of the first language within the home context once children have entered a second-language-dominant preschool setting.

Finally, the findings of the present study suggest that although the number of parental years of residence in Norway may be a covariate with other important variables, it may not constitute a unique predictor of young DLLs' first- and second-language vocabulary outcomes. That being said, it may also be the case that the influence of parental length of residence in the host country may be more pronounced as DLLs grow into preadolescence (see, for instance, Westeren et al., 2018). Nonetheless, it is an important finding of the present study that the initial differences between home-language groups in young DLLs' first-language vocabulary scores appeared to be far less pronounced when the child- and family-level factors were included in the analytic models. In fact, only children born to the most recent immigrants to Norway, the Polish-speaking group, had significantly stronger first-language vocabulary scores in our models. However, the finding that the Polish-speaking children in the present sample had stronger first-language vocabulary skills compared to other home-language groups may also indicate that unmeasured factors related to heritage language support (e.g., parental fluency, intention to return to the country of origin in the near future, or access to heritage culture and language networks) supported these children's first-language maintenance.

\section{Limitations of the present study}

The results of the present study should be interpreted with caution as the findings may certainly be partly explained by the fact that the assessments were not equivalent across the different first-language translations. We should also underscore that this is a convenience sample that may not represent the population in general. The discrepancy in findings related to the role of demographic factors across studies of DLLs may be related to sample and assessment characteristics, but, in any case, it 
reminds us of the need to be careful about generalizing the findings of the present study to specific populations. For instance, it should be noted that the researcher-developed vocabulary assessments used in the present study were based on words selected from children's books, which may render these tests more responsive to variability in the home literacy environment.

In the present study, we did not include the measures of parental exposure in the structural equation models as parental relative language use when addressing the child appeared to be less predictive of child vocabulary outcomes. Parent-reported estimates of exposure may not be equivalent to observed naturalistic measures, which are typically more consistently predictive of young DLLs' proficiency (Marchman, Martinez, Hurtado, Grüter \& Fernald., 2017).

Further research into the quality aspects of home interactions may yield additional knowledge about the interrelations between children's skill levels in their first and second languages (see, for instance, Quiroz et al., 2010). The relatively high correlation between children's first- and second-language skills detected in the present study suggests that more research is needed to understand the mechanisms that support bilingual vocabulary development across languages among DLLs. Nonetheless, by exploiting the huge variability that exists among young DLLs who are born to immigrant parents in Norway, the present study has identified some of the complex processes that are associated with the variability in young DLLs' firstand second-language vocabulary development.

Acknowledgements. We would like to express our appreciation to all the parents and children who contributed their time and interest in this study. We also want to thank the research assistants who helped with translations and data collection. The overall project was financed by the Research Council of Norway (grant number 218280).

\section{References}

Bedore, L. M., Peña, E. D., Summers, C. L., Boerger, K. M., Resendiz, M. D., Greene, K., \& Gillam, R. B. (2012). The measure matters: Language dominance profiles across measures in Spanish-English bilingual children. Bilingualism: Language and Cognition, 15(3), 616-629.

Bohman, T. M., Bedore, L. M., Peña, E. D., Mendez-Perez, A., \& Gillam, R. B. (2010). What you hear and what you say: Language performance in Spanish-English bilinguals. International Journal of Bilingual Education and Bilingualism, 13(3), 325-344.

Bridges, K., \& Hoff, E. (2014). Older sibling influences on the language environment and language development of toddlers in bilingual homes. Applied Psycholinguistics, 35(2), 225-241.

De Houwer, A. (2007). Parental language input patterns and children's bilingual use. Applied Psycholinguistics, 28(3), 411-424.

Dixon, L. Q., Wu, S., \& Daraghmeh, A. (2012a). Profiles in bilingualism: Factors influencing kindergartners' language proficiency. Early Childhood Education Journal, 40(1), 25-34.

Dixon, L. Q., Zhao, J., Quiroz, B. G., \& Shin, J. Y. (2012b). Home and community factors influencing bilingual children's ethnic language vocabulary development. International Journal of Bilingualism, 16 (4), 541-565.

Dunn, L. M., Dunn, L. M., Whetton, C., \& Burley, J. (1997). The British Picture Vocabulary Scale (2nd ed.). London: Nelson.

Durham, R. E., Farkas, G., Hammer, C. S., Tomblin, J. B., \& Catts, H. W. (2007). Kindergarten oral language skill: A key variable in the intergenerational transmission of socioeconomic status. Research in Social Stratification and Mobility, 25(4), 294-305.

Duursma, E., Romero-Contreras, S., Szuber, A., Proctor, P., Snow, C., August, D., \& Calderón, M. (2007). The role of home literacy and language environment on bilinguals' English and Spanish vocabulary development. Applied Psycholinguistics, 28(1), 171-190. 
Ergül, C., Sarica, A. D., Akoglu, G., \& Karaman, G. (2017). The Home Literacy Environments of Turkish Kindergarteners: Does SES Make a Difference? International Journal of Instruction, 10(1), 187-202.

Fernald, A., Marchman, V. A., \& Weisleder, A. (2013). SES differences in language processing skill and vocabulary are evident at 18 months. Developmental Science, 16(2), 234-248.

Gathercole, V. C., \& Thomas, E. M. (2009). Bilingual first-language development: Dominant language takeover, threatened minority language take-up. Bilingualism, 12 (2), 213-237.

Grøver, V., Lawrence, J., \& Rydland, V. (2016). Bilingual preschool children's second-language vocabulary development: The role of first-language vocabulary skills and second-language talk input. International Journal of Bilingualism, 22(2), 234-250.

Grøver, V., Rydland, V., Gustafsson, J. E., \& Snow, C. E. (2020). Shared Book Reading in Preschool Supports Bilingual Children's Second-Language Learning: A Cluster-Randomized Trial. Child Development. https://doi:10.1111/cdev.13348

Hammer, C. S., Davison, M. D., Lawrence, F. R., \& Miccio, A. W. (2009). The effect of maternal language on bilingual children's vocabulary and emergent literacy development during Head Start and kindergarten. Scientific Studies of Reading, 13(2), 99-121.

Hammer, C. S., Komaroff, E., Rodriguez, B. L., Lopez, L. M., Scarpino, S. E., \& Goldstein, B. (2012). Predicting Spanish-English bilingual children's language abilities. Journal of Speech, Language, and Hearing Research, 55(5), 1251-1264.

Hoff, E. (2003). The specificity of environmental influence: Socioeconomic status affects early vocabulary development via maternal speech. Child Development, 74(5), 1368-1378.

Hoff, E., Core, C., Place, S., Rumiche, R., Señor, M., \& Parra, M. (2012). Dual language exposure and early bilingual development. Journal of Child Language, 39(1), 1-27.

Karlsen, J., Lyster, S. A. H., \& Lervåg, A. (2017). Vocabulary development in Norwegian L1 and L2 learners in the kindergarten-school transition. Journal of Child Language, 44(2), 402-426.

Lervåg, A., \& Grøver Aukrust, V. (2010). Vocabulary knowledge is a critical determinant of the difference in reading comprehension growth between first and second language learners. Journal of Child Psychology and Psychiatry, 51(5), 612-620.

Lohndorf, R. T., Vermeer, H. J., Carcamo, R. A., \& Mesman, J. (2018). Preschoolers' vocabulary acquisition in Chile: the roles of socioeconomic status and quality of home environment. Journal of Child Language, 45(3), 559-580.

Lyster, S.-A. H., Horn, E., \& Rygvold, A.-L. (2010). Ordforråd og ordforrådsutvikling hos norske barn og unge: resultater fra en utprøving av British Picture Vocabulary Scale II, second edition [Vocabulary and vocabulary development in Norwegian children and youth: results from testing with British Picture Vocabulary Scale II]. Spesialpedagogikk, 9, 35-43.

Mancilla-Martinez, J., \& Lesaux, N. K. (2011). The gap between Spanish speakers' word reading and word knowledge: A longitudinal study. Child Development, 82(5), 1544-1560.

Marchman, V. A., Martinez, L. Z., Hurtado, N., Grüter, T., \& Fernald, A. (2017). Caregiver talk to young Spanish-English bilinguals: comparing direct observation and parent-report measures of dual-language exposure. Developmental Science, 20(1), e12425. https://doi-org.ezproxy.uio.no/10.1111/desc.12425

McCabe, A., Tamis-LeMonda, C. S., Bornstein, M. H., Cates, C. B., Golinkoff, R., Guerra, A. W., Hirsh-Pasek, K., Hoff, E., Kuchirko, Y., Melzi, G., Mendelsohn, A., Páez, M., \& Song, L. (2013). Multilingual children: Beyond myths and towards best practices. Social Policy Report, 27(4), 1-37.

Muthén, L. K., \& Muthén, B. O. (1998-2017). Mplus user's guide (8.th ed.). Los Angeles, CA.: Author.

Palermo, F., Mikulski, A. M., Fabes, R. A., Hanish, L. D., Martin, C. L., \& Stargel, L. E. (2014). English exposure in the home and classroom: Predictions to Spanish-speaking preschoolers' English vocabulary skills. Applied Psycholinguistics, 35(6), 1163-1187.

Pena, E. D., \& Halle, T. G. (2011). Assessing preschool dual language learners: Traveling a multiforked road. Child Development Perspectives, 5(1), 28-32.

Place, S., \& Hoff, E. (2016). Effects and noneffects of input in bilingual environments on dual language skills in $2 \frac{1}{2}$-year-olds. Bilingualism: Language and Cognition, 19(5), 1023-1041.

Prevoo, M. J., Malda, M., Mesman, J., Emmen, R. A., Yeniad, N., van Ijzendoorn, M. H., \& Linting, M. (2014). Predicting ethnic minority children's vocabulary from socioeconomic status, maternal language and home reading input: different pathways for host and ethnic language. Journal of Child Language, 41 (5), 963-984. 
Quiroz, B. G., Snow, C. E., \& Zhao, J. (2010). Vocabulary skills of Spanish-English bilinguals: impact of mother-child language interactions and home language and literacy support. International Journal of Bilingualism, 14(4), 379-399.

Ribot, K. M., \& Hoff, E. (2014). “ ¿ Cómo estas?”“I’m good.” Conversational code-switching is related to profiles of expressive and receptive proficiency in Spanish-English bilingual toddlers. International Journal of Behavioral Development, 38(4), 333-341.

Ribot, K. M., Hoff, E., \& Burridge, A. (2018). Language use contributes to expressive language growth: Evidence from bilingual children. Child Development, 89(3), 929-940.

Rojas, R., Iglesias, A., Bunta, F., Goldstein, B., Goldenberg, C., \& Reese, L. (2016). Interlocutor differential effects on the expressive language skills of Spanish-speaking English learners. International Journal of Speech-Language Pathology, 18(2), 166-177.

Rydland, V., Grøver Aukrust, V., \& Fulland, H. (2013). Living in neighborhoods with high or low co-ethnic concentration: Turkish-Norwegian-speaking students' vocabulary skills and reading comprehension. International Journal of Bilingual Education and Bilingualism, 16(6), 657-674.

Rydland, V., Grøver, V., \& Lawrence, J. (2014). The second-language vocabulary trajectories of Turkish immigrant children in Norway from ages five to ten: the role of preschool talk exposure, maternal education, and co-ethnic concentration in the neighborhood. Journal of Child Language, 41(2), 352-381.

Scheele, A. F., Leseman, P. P., \& Mayo, A. Y. (2010). The home language environment of monolingual and bilingual children and their language proficiency. Applied Psycholinguistics, 31(1), 117-140.

Snow, C. E. (2017). The role of vocabulary versus knowledge in children's language learning: a fifty-year perspective/El papel del vocabulario frente al conocimiento en el aprendizaje lingüístico de los niños: una perspectiva de cincuenta años. Infancia y Aprendizaje, 40(1), 1-18.

Westeren, I., Halberg, A. M., Ledesma, H. M., Wold, A. H., \& Oppedal, B. (2018). Effects of mother's and father's education level and age at migration on children's bilingual vocabulary. Applied Psycholinguistics, 39(5), 811-833.

Winsler, A., Burchinal, M. R., Tien, H. C., Peisner-Feinberg, E., Espinosa, L., Castro, D. C., \& De Feyter, J. (2014). Early development among dual language learners: The roles of language use at home, maternal immigration, country of origin, and socio-demographic variables. Early Childhood Research Quarterly, 29(4), 750-764.

Winsler, A., Kim, Y. K., \& Richard, E. R. (2014). Socio-emotional skills, behavior problems, and Spanish competence predict the acquisition of English among English language learners in poverty. Developmental Psychology, 50(9), 2242-2254.

Cite this article: Rydland V, Grøver V (2021). Language use, home literacy environment, and demography: Predicting vocabulary skills among diverse young dual language learners in Norway. Journal of Child Language 48, 717-736. https://doi.org/10.1017/S0305000920000495 